\title{
The Effect of Mode of Delivery on Newborn Hearing Screening Results
}

\author{
Original Investigation \\ Selis Gülseven Güven (1) \\ Department of Otorhinolaryngology, Trakya University School of Medicine, Edirne, Turkey
}

Abstract

ORCID ID of the author:

S.G.G. 0000-0002-7862-0758.

Cite this article as: Güven SG. The Effect of Mode of Delivery on Newborn Hearing Screening Results. Turk Arch Otorhinolaryngol 2019; 57(1): 19-23.

This study was presented at the $7^{\text {th }}$ International Trakya Family Medicine Congress, March 21-25, 2018, Edirne, Turkey.

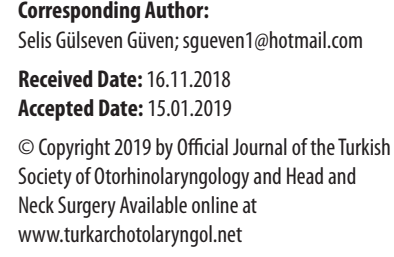

Objective: Congenital hearing loss is one of the most important public health problems with a frequency of about 1-6 per 1000 live births all over the world. Although neonatal hearing screening tests are important for the timely detection and rehabilitation of hearing loss, determining the factors that may affect the screening results will contribute greatly to the development of screening programs. In this study, the effects of the modes of delivery on the results of tests in the screening program was investigated.

Methods: In this study, the results of 10.575 newborns who were screened according to the National Neonatal Hearing Screening Protocol between January 2013 and May 2017 were evaluated. The screening test results of 2.653 newborns were examined retrospectively according to the type of delivery after candidates were excluded according to the exclusion criteria and risk factors for hearing loss. Of these newborns, 1.571 (59.2\%) were born by normal deliv- ery and $1.082(40.8 \%)$ by cesarean section. Screening test results were analyzed using Pearson's Chi-square test.

Results: No statistically significant difference was observed among the 2.653 neonatal hearing screening test results in terms of mode of delivery $(p>0.05)$. In both delivery modes, the rate of false positive was found to be high (81.9\%) in the first hearing screening test of newborns, and this rate decreased in the second screening test (14.5\%).

Conclusion: The mode of delivery has no significant effect on the neonatal hearing screening results; however, the observation that neonates had been more successful in the second screening test in both groups suggests that the test protocol should be re-evaluated in terms of timing.

Keywords: Mode of delivery, hearing, neonatal screening, otoacoustic emissions

\section{Introduction}

Congenital hearing loss is one of the most important public health problems around the world with a frequency of 1 to 6 in every 1000 live births $(1,2)$. In the absence of adequate external stimuli it can cause delay in speech and language development, underdevelopment in mental activities and learning difficulties that can in turn lead to academic failure as well as social problems (3). In this context, neonatal hearing screening tests have a major place in preventive healthcare services. Implemented in Turkey since 2004, the program was renamed as The National Hearing Screening Program by the Turkish Ministry of Health as of 2014. This program aims to enable all infants to access hearing screening before one month of age.
The World Health Organization and The Hearing Loss Committee recommend identifying hearing loss in children within the first three months and initiating rehabilitation within the first six months (4). Unless checked as part of a screening program, hearing loss in an infant can be diagnosed approximately between months 12 to 36 which is a very valuable period of infant development $(5,6)$.

The National Hearing Screening Program for newborns uses the Transient Evoked Otoacoustic Emissions (TEOAE) and Auditory Brainstem Response (ABR) tests. Hearing loss is more prevalent among newborns who have the risk factors defined by The American Academy of Pediatrics 
Joint Committee on Infant Hearing in 1994 (1. TORCH [toxoplasmosis, rubella, cytomegalovirus, herpes, syphilis]; 2. Family history of childhood sensorineural hearing loss; 3. Craniofacial anomalies involving external auditory canal and the pinna; 4. Premature newborns with a birth weight less than 1500 grams; 5. Hyperbilirubinemia at a serum level requiring exchange transfusion; 6. Ototoxic medications (including aminoglycosides, used in multiple courses or in combination with loop diuretics); 7. Bacterial meningitis; 8 . Apgar scores of 0 to 4 at the first minute, 0 to 6 at the fifth minutes; 9. Infants administered mechanical ventilation for more than five days; 10 . Symptoms associated with a syndrome known to accompany a sensorineural and/or conductive hearing loss) $(7,8)$. In this regard, each of these risk factors are considered in scope of the screening program.

Investigating other factors that may affect screening test results will nevertheless contribute to the improvement of screening programs. To that end, the effects which the mode of delivery has on the hearing screening test results of newborns has been investigated in the presented study.

\section{Methods}

This is a cross-sectional study conducted from January 2013 to May 2017 on the hearing screening test results of newborns in the Tekirdağ Çorlu State Hospital. Hearing screening test results of 2.653 infants who did not have any of the risk factors defined for hearing loss and did not match the other predefined exclusion criteria of the study were examined. Permission from the relevant institutions and approval from the Trakya University School of Medicine Ethics Comittee of Scientific Researches were obtained. Written informed consent was not obtained from patients' families since national newborn hearing screening data would be retrospectively evaluated.

Hearing screening tests of newborns were performed by trained staff in a quiet environment at the newborn hearing screening unit of the hospital. Care was taken to keep the infants quiet and still, therefore, either seated in their mother's lap or laid on a stretcher during screening. After their ears were cleaned against the possibility of amniotic fluid or vernix caseosa accumulation in the external auditory canals, a probe was placed in the external auditory canal in the size of the canal's diameter and screening tests were performed. A Madsen AccuScreen (GN Otometrics A/S, Taastrup, Denmark) device was used for the TEOAE ABR tests.

Depending on the screening protocol applicable at the date the study data were collected, the first emission test (OAE1) was performed within the first few days after birth. Those who did not pass this test were invited for the second emission test (OAE2) after 15 days; those who did not pass this second test were invited for an ABR test after 15-20 days. Infants who did not pass the ABR test were referred to a tertiary healthcare institution for more advanced hearing tests. Infants born in the hospital are referred to the new- born hearing screening unit 24 hours after birth and immediately before discharge if born by normal delivery, and 48 hours after birth and immediately before discharge if born by cesarean section (C-section). In cases which discharge coincides with the weekend, patients are asked to come for screening on the next working day. Accordingly, the OAE1 test was performed minimum 24 hours and maximum 96 hours after birth.

A total of 10.575 newborns were screened in the above-mentioned time period. The following criteria were determined to exclude other factors other than the mode of delivery as much as possible.

1. Having any of the risk factors defined by the American Academy of Pediatrics Joint Committee on Infant Hearing in 1994,

2. Being born in a center other than the hospital where this study was conducted,

3. Having stayed in the intensive care unit after birth with or without mechanical ventilation,

4. Having been born outside of the full-term birth window (37-42 weeks gestation),

5. Presence of any other identified congenital health problems.

Any newborns who were indicated to have any one of the five criteria above in their hearing screening file were excluded from the study in the initial review. Eventually, hearing screening data of 2.653 infants were included in the study and analyzed based on mode of delivery.

\section{Statistical Analysis}

The data was analyzed using the Statistical Package for Social Science version 22.0 software (IBM Corp.; Armonk, NY, USA). The study is a cross-sectional study. Once all descriptive analyses were completed, quantitative data was compared using Pearson's Chi-square test for statistical evaluation. With $\alpha$ significance level of 0.05 , strength of the evidence was found 0.798 .

\section{Results}

Of the 2.653 infants 1.571 (59.2\%) were born by normal delivery and $1.082(40.8 \%)$ by C-section; and $481(18.1 \%)$ passed the OAE1 test, $1.856(69.9 \%)$ passed the OAE2 test, 296 (11.2\%) passed the ABR test, while 20 (0.8\%) were suspected of hearing loss and referred to a tertiary healthcare facility. These numbers show the number of infants who have successfully completed the hearing screening test in both ears in the OAE1, OAE2 and ABR tests. In other words, hearing screening was completed in both ears of 481 infants in the OAE1 test; of 1,856 infants in the OAE2 test; and of 296 infants in the ABR test. Of the remaining 20 infants, 14 failed the screening tests in both ears, six failed in one ear, and thereby referred to a tertiary healthcare facility. Of the 14 infants who failed the screening tests in both ears, 10 were born by normal delivery and four by $\mathrm{C}$-section. Of the six infants who failed the screening tests in one ear, two were born by normal delivery and four by $\mathrm{C}$-section. 
Table 1. Distribution of newborns by test results based on mode of delivery $(\mathrm{p}=0.417)$

\begin{tabular}{|c|c|c|c|c|}
\hline \multirow[b]{2}{*}{ MODE OF DELIVERY } & \multicolumn{3}{|c|}{ STAGES USED IN HEARING SCREENING } & \multirow[b]{2}{*}{ REFERRAL\% } \\
\hline & OAE1 \% & OAE2 \% & $\mathrm{ABR} \%$ & \\
\hline \multirow[t]{2}{*}{ Normal Delivery $(\mathrm{n}=1.571)$} & 269 & 1.109 & 181 & 12 \\
\hline & $17.1 \%$ & $70.6 \%$ & $11.5 \%$ & $0.8 \%$ \\
\hline \multirow[t]{2}{*}{ C-Section ( $\mathrm{n}=1.082)$} & 212 & 747 & 115 & 8 \\
\hline & $19.6 \%$ & $69 \%$ & $10.7 \%$ & $0.7 \%$ \\
\hline \multirow[t]{2}{*}{ Total $(n=2.653)$} & 481 & 1856 & 296 & 20 \\
\hline & $18.1 \%$ & $69.9 \%$ & $11.2 \%$ & $0.8 \%$ \\
\hline
\end{tabular}

C-Section: cesarian section; ABR: auditory brainstem response; OAE1: initial otoacoustic emission test; OAE2: second otoacoustic emission test

Out of the 2.653 infants 1.856 (69.9\%) successfully completed the screening in the OAE2 stage, while 2.172 (81.9\%) failed the screening in the OAE1 stage. Out of the infants born by normal delivery, 269 (17.1\%) passed the OAE1 test, 1.109 (70.6\%) passed the OAE2 test, 181 (11.5\%) passed the ABR test, and $12(0.8 \%)$ failed all tests and referred to another facility. Out of the infants born by C-section, 212 (19.6\%) passed the OAE1 test, 747 (69\%) passed the OAE2 test, 115 (10.7\%) passed the ABR test, and $8(0.7 \%)$ were referred to another facility (Table 1). False positive rates (outcomes that required a second screening and further evaluation in the absence of actual hearing loss) in infants born by normal delivery were $82.9 \%$ in the OAE1 test, $14.82 \%$ in the OAE2 test, and $6.21 \%$ in the ABR test. Similarly, false positive rates in infants born by C-section were $80.4 \%$ in the OAE1 test, $14.13 \%$ in the OAE2 test, and $6.5 \%$ in the ABR test. In both modes of delivery false positive rates were seen to be high (81.9\%) in the first hearing screening and have significantly decreased (14.5\%) in the second screening (Figure 1).

Accordingly, most of the infants were seen to have passed the screening test in the OAE2 stage, and no statistically significant difference was found with respect to the mode of delivery $(\mathrm{p}=0.417)$. In both delivery modes, most of the infants were seen to have passed the screening test in the OAE2 stage and more than half were seen to have failed in the OAE1 stage.

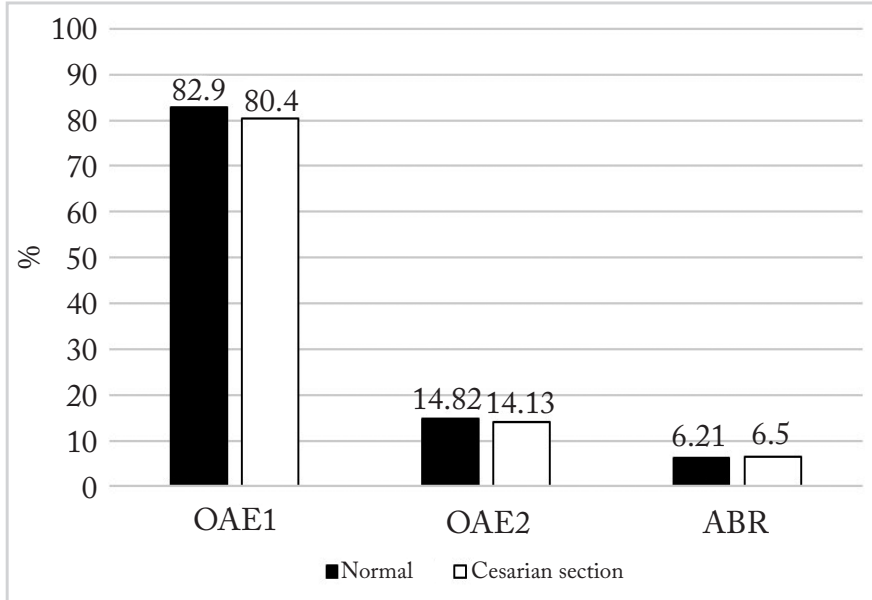

Figure 1. False positive rates by mode of delivery in stages of hearing screening

\section{Discussion}

Since hearing loss is an important public health problem, the importance of neonatal hearing screening is an important preventive health service. Therefore, identifying the factors that may affect screening test results will contribute to the improvement of these programs. In this study, we investigated the effects of mode of delivery on neonatal hearing screening results.

The study was conducted on the screening results of 2.653 infants with a high strength of the evidence and showed that in both modes of delivery most of the infants failed the first screening test while a majority successfully completed the test in the OAE2 stage. Almost all of the infants successfully completed the screening in the ABR stage. In terms of delivery modes, no statistical significance was identified between the successful screening outcomes or the rates of the referred infants.

Xiao et al. (9) retrospectively reviewed the screening results of 1.460 infants to investigate the association between mode of delivery and failure in neonatal acoustic emission test and found significantly high rates of failure in the first emission test among those born by $\mathrm{C}$-section. When they grouped the OAE1 results based on the timing of screening, infants born by $\mathrm{C}$-section and screened within the first 42 hours after birth had significantly higher failure rates, while infants born by $\mathrm{C}$-section and screened after 42 hours still had higher failure rates but not at a statistically significant level. Failure rates in OAE1 were seen to decrease in both modes of delivery as the time from birth to screening increased. Otoacoustic emission tests were repeated before discharge in infants who had failed the OAE1 test. Results of the second screening showed lower failure rates as time elapsed, however, failure rates remained higher in those born by $\mathrm{C}$-section, but with insignificant difference between the two delivery modes at the $60^{\text {th }}$ hour. In other words, as time elapsed no significant differences were found among the failure rates with respect to the two modes of delivery. In their study which Smolkin et al. (10) reviewed the screening results of 1.653 infants, the researchers similarly found significantly higher failed OAE1 results in infants born by $\mathrm{C}$-section compared to those born by normal delivery and associated this outcome with amniotic fluid accumulation in the middle ear. In their report, the authors emphasize that performing the OAE1 screening beyond 48 hours after birth would reduce failure rates, hence minimize 
maternal anxiety and costs. In another study by Smolkin et al. (11), 1.126 infants born by $\mathrm{C}$-section were separated into two groups. OAE1 was performed within the 48 hours after birth in one group and beyond 48 hours in the other and the results were compared. Also in this study, OAE1 failure rates were found 7.7-fold lower in the second group, i.e. in infants screened beyond 48 hours after birth and the need for repeated hearing tests was six-fold lower versus the other group. In another study infants were separated into three groups: the first group was screened at the first 24 hours, the second group between the $24^{\text {th }}$ and $36^{\text {th }}$ hours, and the third group beyond 36 hours after birth. OAE1 success rates were found higher in the second and third groups compared to the first group. The authors indicate that the probability of failure in OAE1 decreased by $5 \%$ with every passing hour (12).

Farahani et al. (13), investigating the effects of the mode of delivery and the type of hospital on the results of neonatal otoacoustic emission tests, particularly focused on false positive rates. Of the 2.784 infants included in the study, 2.444 received the OAE1 test, 332 the OAE2 test, and eight the ABR test. False positive rate was found 1.5-fold higher among those born by normal delivery than in those born by $\mathrm{C}$-section. While false positive rates decreased as time elapsed in those born by $\mathrm{C}$-section, such decrease was not seen in those born by normal delivery. A sharp drop was seen in false positive rates in the OAE2 tests performed in the second week after birth and no significant differences were identified with respect to the modes of delivery. Regarding that false positive rates are higher in infants born by normal delivery, the results of this study are comparable to those reported by Farhadi et al. (14) and by Olusanya and Bamigboye (15), but different to the results reported by Xiao et al. (9) and Smolkin et al. (10). In their study Farahani et al. (13) associated the higher false positive rates in infants born by normal delivery, with low tympanic membrane mobility and delayed absorption of middle ear fluid. Similarly, Xiao et al. (9) also suggested that the same outcome could be seen in infants born by $\mathrm{C}$-section.

In our study, no differences were identified between the two modes of delivery in terms of OAE1 failure rates, but failure rates were seen to comparably decrease as time increased in both delivery modes. In other words, failure rates in OAE1 were high in both delivery modes, possibly due to low tympanic membrane mobility or amniotic fluid accumulation in the middle ear, in the early postnatal period (min. 24 hours - max. 96 hours), while in the OAE2 test performed after time has passed (min. 16 days - max. 20 days) failure rates decreased in both delivery modes, possibly due to resorption of the fluid, and success rates are seen to significantly increase. Torrico et al. (16) recommend performing the OAE1 test as late as possible before discharge and beyond 48 hours after birth, and to repeat the test at least six days after the first test in case of failure. Sequi-Canet et al. (17) in their study indicate breastfeeding to be the major factor in the successful result of an otoacoustic emission test performed within the first 48 hours after birth in infants born by normal delivery. In our study, the possible reasons for the distinct increase in the success rates achieved in the OAE2 test are thought to be the growth of the infant, breastfeeding and absorption of the fluid in the middle ear.

The data analyzed in this study suggest that mode of delivery has no effect on the success of neonatal hearing screening tests; however, when evaluated together with the results reported in the literature, possible amniotic fluid and debris accumulation in the outer ear and the middle ear may affect success in OAE1 screening in the early post-natal period. Given that this condition leads to false positive OAE1 results in both modes of delivery, optimal timing of the first test gains more importance. Therefore, we suggest postponing the screening tests until fluids are resorbed. As also recommended by The World Health Organization, hearing loss should be diagnosed within the first three months and rehabilitation should be initiated within the first six months. To date there is no global consensus on the optimal timing of the OAE1 (18). High false positive result rates obtained in tests performed before discharge within the first few days after birth with concerns that parents are unmindful and incognizant of the severity of the condition would not later bring in their babies for screening, evidently do not contribute much to the screening outcomes in practice. Therefore, to ensure that infants are not neglected, I believe that family doctors could have a role in this process just as they play a leading role in preventive health services for vaccination monitoring.

As demonstrated in the results of this study, performing the OAE1 test 15 days to 1 month after birth will, regardless of the mode of delivery, can eliminate the possibility of false positive in hearing loss, and most infants can successfully pass the screening test. This will further allay unnecessary parental anxiety, eliminate loss of labor and time, and reduce costs.

\section{Conclusion}

The mode of delivery was not identified to have a significant effect on the results of neonatal hearing screening tests. $\mathrm{Nev}^{-}$ ertheless, given that infants, regardless of the mode of delivery, were observed to be more successful in the second screening test suggests that the testing protocol should be revisited in terms of timing of the screening.

Ethics Committee Approval: Ethics committee approval was received for this study from the Trakya University School of Medicine Ethic Comittee of Scientific Researches (TÜTF-BAEK 2018/270).

Informed Consent: Informed consent was not received due to the retrospective nature of the study.

Peer-review: Externally peer-reviewed.

Acknowledgements: I would like to thank the employees of Tekirdağ Çorlu State Hospital Newborn Hearing Screening Unit for their help in obtaining the data of this study.

Conflict of Interest: The authors have no conflicts of interest to declare.

Financial Disclosure: The authors declared that this study has received no financial support. 


\section{References}

1. Akdaş FV. Çocuklarda Sensörinöral İşitme Kayıpları. Çelik O. Kulak Burun Boğaz Hastalıkları ve Baş Boyun Cerrahisi. İstanbul: Turgut Yayınc1lık; 2002. pp. 57-70.

2. Kaynak S, Selçuk KT, Karadaş A. Bandırma Devlet Hastanesi Yenidoğan İşitme Taraması Sonuçları (2011-2014). İzmir Kâtip Çelebi Üniversitesi Sağlık Bilimleri Fakültesi Dergisi 2016; 1: 9-12.

3. Fitzpatrick EM, Durieux-Smith A, Whittingham J. Clinical practice for children with mild bilateral and unilateral hearing loss. Ear Hear 2010; 31: 392-400. [CrossRef]

4. Joint Committee on Infant Hearing (JCIH). Position statement: Principles and guidelines for early hearing detection and intervention programs. Pediatrics 2007; 120: 898-921. [CrossRef]

5. Özkurt FE, Özdoğan F. Yenidoğanlarda otoakustik emisyon işitme taraması sonuçlarımız. KBB-Forum 2012; 11: 23-5.

6. Başar F, Aygün C, Güven A. Ondokuz Mayıs Üniversitesi yenidoğan işitme taraması (YEDİT) ilk yıl sonuçları. OMÜ Tıp Dergisi 2007; 24: 43-51.

7. Joint Committee on Infant Hearing 1994 Position statement. Pediatrics 1995; 95: 152-6.

8. Karasalihoğlu AR. Kulak Burun Boğaz Hastalıkları ve Baş-Boyun Cerrahisi. 3. Baskı Ankara: Güneş Kitabevi; 2003.p. 75-8.

9. Xiao T, Li Y, Xiao L, Jiang L, Hu Q. Association between mode of delivery and failure of neonatal acoustic emission test: a retrospective analysis. Int J Pediatr Otorhinolaryngol 2015; 79: 516-9. [CrossRef]

10. Smolkin T, Mick O, Dabbah M, Blazer S, Grakovsky G, Gabay $\mathrm{N}$, et al. Birth by cesarean delivery and failure on first otoacoustic emissions hearing test. Pediatrics 2012; 130: e95-100. [CrossRef]
11. Smolkin T, Awawdeh S, Blazer S, Mick O, Makhoul IR. Delayed first otoacoustic emissions test decreases failure on neonatal hearing screening after caesarean delivery. Acta Paediatr 2013; 102: e194-9. [CrossRef]

12. Lupoli Lda M, Garcia L, Anastasio AR, Fontana AC. Time after birth in relation to failure rate in newborn hearing screening. Int J Pediatr Otorhinolaryngol 2013; 77: 932-5. [CrossRef]

13. Farahani F, Hamidi Nahrani M, Seifrabiei MA, Emadi M. The effect of mode of delivery and hospital type on newborn hearing screening results using otoacoustic emissions: Based on screening age. Indian J Otolaryngol Head Neck Surg 2017; 69: 1-5. [CrossRef]

14. Farhadi M, Mahmoudian S, Mohammad K, Daneshi A. The pilot study of a nationwide neonatal hearing screening in Iran: Akbarabadi and Mirzakouchak-Khan hospitals in Tehran (June 2003-October 2004). Hakim Res J 2006; 9: 65-75.

15. Olusanya BO, Bamigboye BA. Is discordance in TEOAE and AABR outcomes predictable in newborns? Int J Pediatr Otorhinolaryngol 2010; 74: 1303-9. [CrossRef]

16. Torrico P, Gómez C, López-Ríos J, de Cáceres MC, Trinidad G, Serrano M. [Age influence in otoacoustic emissions for hearing loss screening in infants]. Acta Otorrinolaringol Esp 2004; 55: 153-9. [CrossRef]

17. Sequi-Canet JM, Sala-Langa MJ, Collar Del Castillo JI. [Perinatal factors affecting the detection of otoacoustic emissions in vaginally delivered, healthy newborns, during the first 48 hours of life]. Acta Otorrinolaringol Esp 2014; 65: 1-7. [CrossRef]

18. Akinpelu OV, Peleva E, Funnell WR, Daniel SJ. Otoacoustic emissions in newborn hearing screening: a systematic review of the effects of different protocols on test outcomes. Int J Pediatr Otorhinolaryngol 2014; 78: 711-7. [CrossRef] 